\title{
Metallomics
}

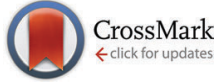

Cite this: Metallomics, 2015 7, 112

Received 3rd October 2014 Accepted 1st December 2014 DOI: $10.1039 / \mathrm{c} 4 \mathrm{mt} 00260 \mathrm{a}$

www.rsc.org/metallomics

\section{Zinc isotopic compositions of breast cancer tissue $\dagger$}

\author{
Fiona Larner, ${ }^{* a b}$ Laura N. Woodley, ${ }^{c}$ Sami Shousha, ${ }^{d}$ Ashley Moyes, ${ }^{e}$ \\ Emma Humphreys-Williams, ${ }^{f}$ Stanislav Strekopytov, ${ }^{f}$ Alex N. Halliday, ${ }^{a}$ \\ Mark Rehkämper bf and R. Charles Coombes ${ }^{\mathrm{g}}$
}

\begin{abstract}
An early diagnostic biomarker for breast cancer is essential to improve outcome. High precision isotopic analysis, originating in Earth sciences, can detect very small shifts in metal pathways. For the first time, the natural intrinsic $\mathrm{Zn}$ isotopic compositions of various tissues in breast cancer patients and controls were determined. Breast cancer tumours were found to have a significantly lighter $\mathrm{Zn}$ isotopic composition than the blood, serum and healthy breast tissue in both groups. The $\mathrm{Zn}$ isotopic lightness in tumours suggests that sulphur rich metallothionein dominates the isotopic selectivity of a breast tissue cell, rather than $\mathrm{Zn}$-specific proteins. This reveals a possible mechanism of $\mathrm{Zn}$ delivery to $\mathrm{Zn}$-sequestering vesicles by metallothionein, and is supported by a similar signature observed in the copper isotopic compositions of one breast cancer patient. This change in intrinsic isotopic compositions due to cancer has the potential to provide a novel early biomarker for breast cancer.
\end{abstract}

\section{Introduction}

Early diagnosis for breast cancer patients is critical to improve outcome, and a biomarker that could detect the disease early could be invaluable. High concentrations of zinc $(\mathrm{Zn})$ have been noted in breast cancer tissue for over a decade. The causative changes in $\mathrm{Zn}$ metabolism at the molecular level have remained elusive $^{1-3}$ and traditional hospital-based measurements of metal metabolism are insufficiently sensitive to provide a diagnostic tool. New techniques for the high precision measurement of natural isotopic compositions are far more sensitive and have recently been used to illuminate previously undetectable trace element biological pathways due to disease ${ }^{4-6}$ but not cancer.

\footnotetext{
${ }^{a}$ Department of Earth Sciences, University of Oxford, South Parks Road, Oxford, OX1 3AN, UK. E-mail: fiona.larner@earth.ox.ac.uk; Tel: +44 (0)1865 282117

${ }^{b}$ Department of Earth Science \& Engineering, Imperial College London, Exhibition Road, South Kensington, London, SW7 2AZ, UK

${ }^{c}$ Experimental Cancer Medicine Centre Network, Imperial College, Fulham Palace Road, London W6 8RF, UK

${ }^{d}$ Department of Histopathology, Charing Cross Hospital, Imperial College, Fulham Palace Road, London W6 8RF, UK

${ }^{e}$ Medical Oncology, Charing Cross Hospital, Imperial College NHS Trust, Fulham Palace Road, London W6 8RF, UK

${ }^{f}$ Department of Earth Sciences, Natural History Museum, Cromwell Road, London, SW7 5BD, UK

${ }^{g}$ Department of Surgery and Cancer, Imperial College London, Du Cane Road, London, W12 ONN, UK

$\dagger$ Electronic supplementary information (ESI) available. See DOI: 10.1039/ c4mt00260a
}

Zinc is an essential trace element required by the human body for more than 300 cellular processes ${ }^{7}$ but can be toxic in excess and therefore requires a high level of regulation. Zinc importer (Zip) and transporter (ZnT) proteins facilitate cellular zinc homeostasis ${ }^{3}$ and several proteins within these families appear disturbed in breast cancer cells. The anti-oxidant protein metallothionein (MT) is also known to have a significant role in cellular Zn metabolism, as well as for other essential metals such as copper. Levels of MT are poorly regulated in breast cancer. ${ }^{2}$ Zinc concentrations have been reported to be significantly higher in breast cancer tumours relative to healthy breast tissue, and lower in blood serum and erythrocytes of breast cancer patients compared to healthy controls. ${ }^{1,2,8,9}$ Increased levels of Zips are present in breast cancer cells ${ }^{2}$ leading to increased $\mathrm{Zn}$ uptake. Whilst some $\mathrm{ZnT}$ proteins promote $\mathrm{Zn}$ efflux by sequestering excess cellular zinc into vesicles for later use, extreme excess zinc triggers cell apoptosis in healthy cells. ${ }^{8}$ However the zinc transporter ZnT2 and MT are thought to be overexpressed in malignant breast cancer cells, ${ }^{2,8}$ which protects them from hyper accumulation of zinc and prevents tumour cell death.

Natural stable isotope fractionation is one of the most sensitive methods for exploring and quantifying environmental processes past and present. The development of multiple collector inductively coupled plasma mass spectrometry (MC-ICP-MS) has facilitated stable isotope measurements for a far broader range of elements than hitherto possible and provided important information about Earth's formation, the evolution of life and mechanisms of climate change. ${ }^{10-12}$ Fractionation occurs when 
the light- or heavy-mass isotope(s) of an element are transformed preferentially or more rapidly in a reaction, as a result of mass dependent differences in the energy budget of the process. This can happen, for example, due to changes in phase, ligand coordination and redox state, or transport processes, including biological uptake. ${ }^{13}$ The tightly controlled energy requirements of biological systems mean the related isotopic fractionation is typically significant, and facilitates a sensitive monitor of metabolic change. In particular, zinc isotope fractionation could differ when a cellular process is altered because of a disease such as cancer; in principle it provides more insight than concentration changes alone. Here we report the results of a pilot investigation of $\mathrm{Zn}$ metabolism in breast cancer, by comparing how the isotopic composition in different reservoirs changes with malignancy.

\section{Results \& discussion}

The $\mathrm{Zn}$ concentration and isotopic composition of blood and blood serum of healthy controls and breast cancer patients were determined, alongside a suite of 10 breast tissues, predominantly obtained from breast cancer patients (Fig. 1; Table 1). As observed in other investigations, ${ }^{1,14}$ the $\mathrm{Zn}$ concentration of tumours was found to be significantly higher than the average values for healthy breast tissue reported in literature ${ }^{1,14}$ and found in this study. The isotopic composition is expressed as the ${ }^{66} \mathrm{Zn} /{ }^{64} \mathrm{Zn}$ ratio. Variations in this composition due to isotopic fractionation are small so are reported as the deviation, $\partial^{66} \mathrm{Zn}$, in parts per thousand (\%o; eqn (1)) relative to a widely available well-characterised source of zinc.

$$
\partial^{66} \mathrm{Zn}(\%)=\left[\left(\left({ }^{66} \mathrm{Zn} /{ }^{64} \mathrm{Zn}\right)_{\text {sample }} /\left({ }^{66} \mathrm{Zn} /{ }^{64} \mathrm{Zn}\right)_{\text {reference }}\right)-1\right] \times 1000
$$

The samples of blood and of serum display limited isotopic variation $\left(\delta^{66} \mathrm{Zn}=-0.1\right.$ to $+0.3 \%$ ). There is no systematic difference between samples from healthy controls or breast cancer patients. A haematoma sample from operation-induced trauma is more negative $(-0.2 \%)$ however. The most negative

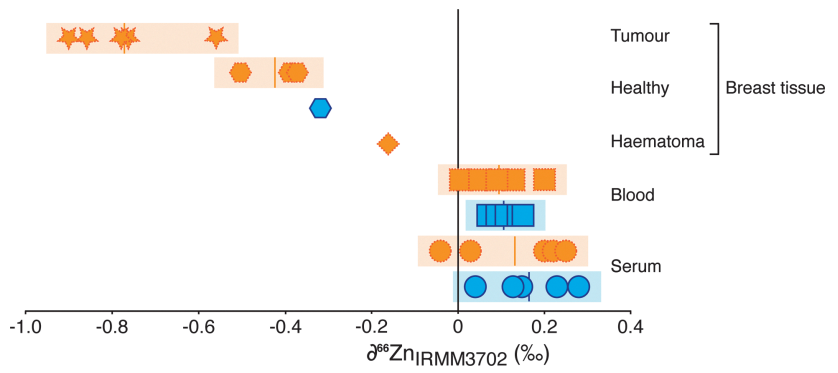

Fig. 1 Variations in zinc isotope composition of breast cancer patients and controls. Zinc isotope composition of blood (squares; $n=10$ ), serum (circles, $n=10$ ), healthy breast tissue (hexagons, $n=4$ ), haematoma (diamond, $n=1$ ) and tumour (stars, $n=5$ ) samples from breast cancer patients (yellow, dashed outline) and age-matched controls (blue, solid outline). Tumours are significantly isotopically light compared to all other tissues. Mean values are shown by horizontal lines in shaded regions. Uncertainty is $\leq \pm 0.2 \%$ (2SD), and is encompassed by shaded regions. values $(-0.6$ to $-0.9 \%$ ) are from breast cancer tissue. Healthy tissue from breast cancer patients and one healthy control show a $\mathrm{Zn}$ isotope composition lighter than blood and serum $(-0.3$ to $-0.5 \%)$, but not as isotopically light as breast cancer tissue. For one patient the healthy tissue was retrieved adjacent to the tumour tissue and demonstrates a $\mathrm{Zn}$ isotope fractionation of approximately $-0.5 \%$ and an isotopic difference of around $-0.9 \%$ between blood and tumour (Fig. 1). Therefore, isotopically lighter zinc appears to be sequestered during tumour formation.

Zinc metabolism in breast tissue is not fully understood, however, it is thought that it is imported into breast cells via Zips, buffered by MT and sequestered into intracellular vesicles by ZnTs, in addition to other interactions which incorporate $\mathrm{Zn}$ into functional roles (e.g. Zn-finger protein formation ${ }^{15}$ ). Zinc isotopic fractionation can occur at any or all of these transformative steps but the net effect must be to produce an isotopically light zinc pool. Ab initio modelling ${ }^{16,17}$ and laboratory-based investigations ${ }^{18}$ of biological $\mathrm{Zn}$ interactions indicate that, because of the stronger bonds formed, heavier isotopes will preferentially bond to amino acids with harder ligands, such as nitrogen and oxygen, whereas lighter isotopes will be found with softer ligands such as sulfur. ${ }^{13}$ Both Zips and ZnTs are noted for their numerous histidine (and therefore nitrogen rich) residues. ${ }^{13}$ Therefore, they are unlikely candidates for developing an isotopically light composition. Metallothionein (MT) in contrast is S rich and capable of binding up to seven $\mathrm{Zn}$ ions with its 20 cysteine residues. Metallothionein, rather than a zinc-specific protein, therefore is most probably responsible for the relatively light $\mathrm{Zn}$ isotope composition of healthy tissue relative to blood, and of tumour tissue relative to its healthy counterpart. The data indicate that the up-regulation of Zips, ZnTs and MT in cancer cells magnifies the same isotopic processes occurring in healthy cells, whereby the selectivity of the MT overrides any heavy isotopic preference induced by the $\mathrm{Zn}$ specific proteins.

This hypothesis is supported by the behaviour of copper $(\mathrm{Cu})$ isotopes in the same tissues (Fig. 2), which we have analysed in a small number of samples (Table 1). Copper is not subject to cell processes governed by $\mathrm{Zn}$-specific proteins, however the isotopic composition of $\mathrm{Cu}$ in the tumour relative to the adjacent healthy tissue is isotopically lighter by $-0.4 \%$ (Fig. 2). Copper management is governed partly by copper-specific proteins, (e.g. ATP7A, B, CTR1, ATOX $1^{19}$ ) as well as metallothionein. There have been no reported up-regulation in $\mathrm{Cu}$-transporter proteins in breast cancer cells, therefore the observed isotopic shift from healthy tissue to tumour is most likely caused by binding of $\mathrm{Cu}$ to increased amounts of MT present in the cell. This indicates that the magnitude of isotopic fractionation of different transition metals by this protein is similar.

To preserve mass balance in the system, the sequestration of isotopically light zinc into breast cancer cells requires an isotopically heavy $\mathrm{Zn}$ pool to be present in the body as the remnant of the original zinc source. Identification of this pool could provide a new method of diagnosis. The difference in 
Table 1 Summary of patient information, zinc and copper isotope compositions and concentration data for individuals and standard materials ${ }^{a}$

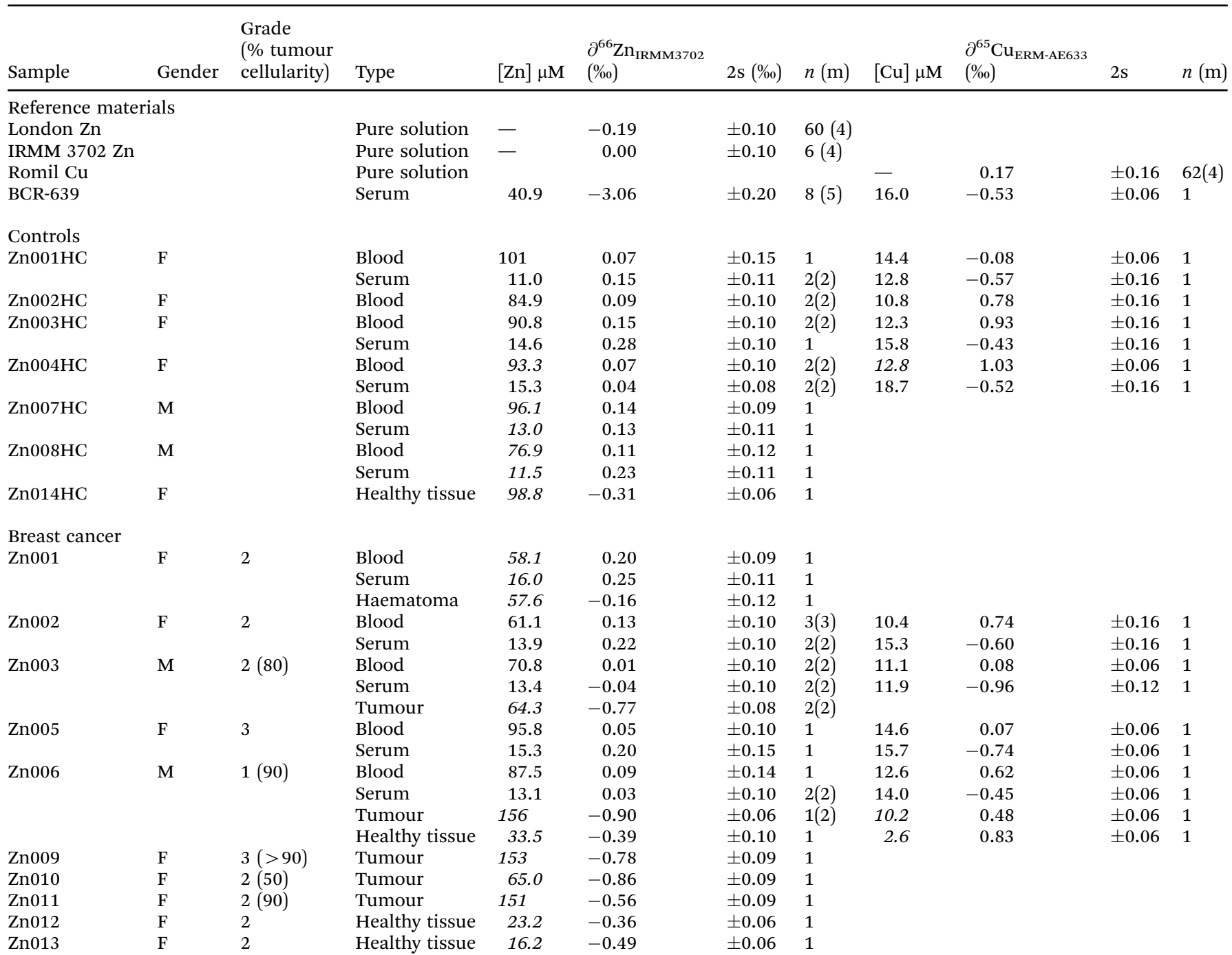

${ }^{a}$ For isotope compositions, $n=$ number of full procedural separations, $m=$ number of analytical sessions on MC-ICP-MS. Italicized concentrations determined from MC-ICP-MS data.

isotope composition of $\mathrm{Zn}$ caused by the tumour is not detectable in the blood or serum of cancer patients relative to healthy controls (Fig. 1). The $\delta^{66} \mathrm{Zn}$ value of blood has been shown to vary by $\pm 0.2 \%$ due to diet, ${ }^{20}$ therefore the normalization of each individual's serum $\mathrm{Zn}$ isotope composition to the blood composition can be used to remove scatter introduced by dietary influence. This, however, does not increase resolution between the two groups, and confirms that the simple measurement of these easily accessible sample types cannot be used to identify the diagnostic heavy $\mathrm{Zn}$ isotope pool if analysed in bulk form.

The mixing of two reservoirs can change the isotopic composition of the resultant pool to varying degrees and is represented by the haematoma sample (blood pool with healthy tissue cells) analysed (Fig. 1). This sample has a $\mathrm{Zn}$ isotopic composition between that of blood and the healthy tissue samples, representing the mixing of the two pools in this sample, whereby the contribution of the healthy tissue cells is large enough to perturb the intrinsic composition of the blood.
Using mixing calculations (see ESI $\dagger$ ) and the average zinc isotope values and concentrations of the blood and tumours measured here, it can be shown that the lack of signal in the blood from tumour growth is to be expected. The background zinc pool in the blood, typically $\sim 5 \mathrm{~L}$ of $100 \mu \mathrm{M} \mathrm{Zn}$, is too large and acts as a buffer to the small reservoir of isotopically heavy excreted zinc originating from the tumour; for example, growth of a $1 \mathrm{~g}$ tumour would perturb the $\mathrm{Zn}$ isotope composition of blood $\left(\Delta^{66} \mathrm{Zn}\right)$ by $<0.0005 \%$.

Although bulk blood does not reveal an isotopic effect it would be important to be able to identify and isolate a more discrete isotopically heavy pool of $\mathrm{Zn}$ that is residual to the light tumour-sequestered $\mathrm{Zn}$. It could provide an important early biomarker for the disease. The mechanism resulting in the expulsion of isotopically heavy $\mathrm{Zn}$ from the tumour cells is key to finding the appropriate compartment containing the biomarker and, for example, could be in white blood cells or a specific protein size fraction from blood. The mass balance of 


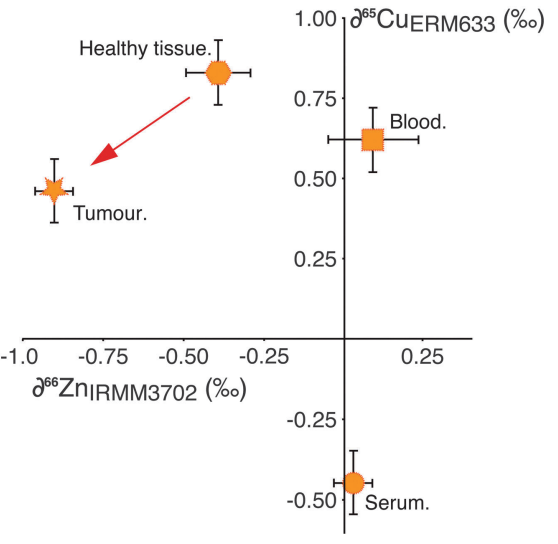

Fig. 2 Zinc and copper isotope compositions of various tissues for one breast cancer patient. The combined $\mathrm{Zn}$ and $\mathrm{Cu}$ isotopic compositions of tumour, healthy tissue, serum and blood of one patient separates the tissues into distinct areas, showing isotopic processes between various body pools. The red arrow highlights similar isotopic behaviour for copper and zinc on the formation of tumour tissue. Uncertainty is $\leq \pm 0.2 \%$ (2SD).

$\mathrm{Zn}$ between the tumour and this unknown heavy pool is unconstrained at present. However, mixing calculations (eqn (S1)-(S7), ESI $\dagger$ ) predict that the residual isotopic signature of the measured heavy pool will be sufficiently different to distinguish between breast cancer patients and healthy controls if the unknown heavy pool represents only $30 \%$ or less of the total $\mathrm{Zn}$ in the reservoir from which it is extracted (Fig. 3; see ESI $\dagger$ for more detailed analysis). Given that tumours are enriched in $\mathrm{Zn}$ this may be possible.

The continuous replenishment of bodily $\mathrm{Zn}$ from the diet could have a significant effect on any relationship between isotopic composition and disease severity. This remains to be properly explored. This pilot data can be linked to up-regulation of particular proteins in breast cancer cells, however, the presence of other cells in cancer, such as those associated with inflammation, ${ }^{21,22}$ and their effect on metal metabolism may also have a mechanistic role which results in the observed isotopic changes. Additional studies are needed to detect any isotopically

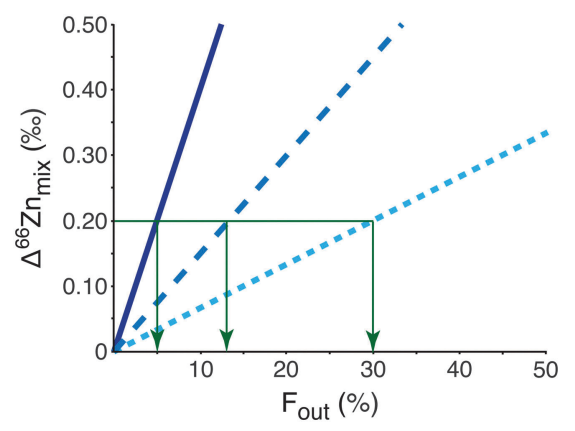

Fig. 3 The predicted zinc pool required for diagnosis using natural isotopic $\mathrm{Zn}$ fractionation. The modelled change in $\mathrm{Zn}$ isotope composition $\left(4^{66} Z_{\text {mix }}\right.$ ) of a diagnostic pool (e.g. white blood cells) due to the effect of the size of the tumour $\mathrm{Zn}$ pool (40\% dotted line, $60 \%$ dashed line, $80 \%$ solid line) on the residual diagnostic pool. An analytical precision of $0.20 \%$ means that at least $5 \%$ of the sampled pool must consist of the unknown heavy $\mathrm{Zn}$ pool $\left(F_{\text {out }}\right)$ to provide a diagnosis. heavy pool and the degree to which this might not only identify cancer and shed light on specific $\mathrm{Zn}$ transfer mechanisms but also indicate the progression of the disease.

\section{Conclusion}

Mechanistic changes in zinc metabolism on tumour formation in breast cancer are reflected in the change of natural intrinsic zinc isotopic composition of breast tissue. Whilst the causes are not certain, this observation implicates the potential use of high precision isotopic analysis to develop a new, early biomarker for breast cancer.

\section{Experimental}

\section{Sample collection}

This study was approved by the Tissue Management Committee of the Imperial College NHS Healthcare Tissue Bank. Informed patient consent was obtained before the collection of samples. Sample collection was performed at Charing Cross Hospital, Imperial College NHS Trust, London UK. Samples were collected in clean Teflon vials from breast cancer patients (blood, serum, tumour, healthy tissue, haematoma) and age matched controls (blood, serum). Tumour and haematoma samples were taken using precleaned ceramic knives, with the exception of three previously collected tumor samples supplied directly from the tissue bank in plastic vials.

\section{Sample preparation}

Samples were prepared for $\mathrm{Zn}$ and $\mathrm{Cu}$ isotopic composition and concentration analysis in Class 10 laminar flow hoods either in the MAGIC Clean Room Laboratory, Imperial College London or at the Clean Laboratory Suite at the University of Oxford. Quartz distilled acids diluted with $18 \mathrm{M} \Omega \mathrm{cm} \mathrm{H}_{2} \mathrm{O}$ (Millipore) if necessary were used throughout for sample preparation. Samples $(0.25-0.5 \mathrm{ml}$ or $<0.5 \mathrm{~g})$ were microwave digested in a $3+2$ mixture of $15 \mathrm{M} \mathrm{HNO}_{3}+30 \% \mathrm{H}_{2} \mathrm{O}_{2}$ (vol/vol) ramping over $90 \mathrm{~min}$ to $210{ }^{\circ} \mathrm{C}, 250$ psi.

\section{Concentration and isotopic analysis}

Zinc and copper concentrations were determined by ICP-AES and ICP-MS at the Natural History Museum, London (Table 1). The $\mathrm{Zn}$ concentrations were used to allow accurate double spiking prior to $\mathrm{Zn}$ isolation from the sample matrix via anion exchange chromatography. ${ }^{23,24}$ Isotope analyses were performed using the $\mathrm{Nu}$ Instruments $\mathrm{Nu}$ Plasma HR MC-ICP-MS at the appropriate resolution mode (Cu: low, $\mathrm{Zn}$ : medium) with either an Aridus (Cetac, ICL) or a DSN (Nu Instruments, Oxford) desolvating sample introduction system. Isotope measurements were performed as previously described..$^{25,26}$ A reference solution was measured at least twice either side of sample analyses to monitor and allow accurate correction of changes in instrumental mass bias, as described previously. ${ }^{23,24,26}$ The data retrieved from the MC-ICP-MS measurements were used to calculate the difference in isotope composition $\left(\delta^{66} \mathrm{Zn}\right.$ or $\left.\delta^{65} \mathrm{Cu}\right)$ 
of a sample (sam) relative to the average of the bracketing standard solutions (std; equation 1), Cu by exponential normalization with nickel ${ }^{24}$ and $\mathrm{Zn}$ by double spike deconvolution. ${ }^{23}$ Isotopic values are reported relative to the well-characterised materials IRMM-3702 (Zn) and ERM-AE633 (Cu). ${ }^{27}$ The $\mathrm{Zn}$ and $\mathrm{Cu}$ blank contribution were monitored to ensure results were not influenced by background levels and was typically $<1 \%$ of the total sample $\mathrm{Zn}$ or $\mathrm{Cu}$ respectively. The reproducibility of the methods were monitored by (i) repeat measurements of an in house standard alongside samples, (ii) the processing and measurement of the same samples through the whole method twice, and (iii) the measurement of a matrix matched standard material, BCR-639 Human serum, with multiple batches of samples (Table 1). The external reproducibility of the in house standard is $\pm 0.10 \%$ o (2SD) and the vast majority of the samples are within this uncertainty, and all are within the reproducibility of the matrix matched standard.

\section{Acknowledgements}

Tissue samples were provided by the Imperial College Healthcare NHS Trust Tissue Bank. Other investigators may have received samples from these same tissues. This study was supported by an ERC Advanced Fellowship to A.N.H., Pfizer (IES) grant PX0602_WSCC to R.C.C. and Impact Acceleration Awards from STFC and EPSRC to M.R and F.L. Author contributions: L.N.W. and A.M. coordinated patient consent and sample collection; S.Sh. provided tissue samples and histopathological data; E.H-W. and S.St. performed concentration analyses; F.L., R.C.C. and M.R. designed the study; A.N.H. was involved in study design and data analysis; A.N.H. and M.R. were involved in manuscript preparation; F.L. digested, separated, performed MC-ICP-MS analyses, analysed the data and wrote the paper. All authors discussed the findings and commented on the manuscript.

\section{References}

1 E. J. Margalioth, J. G. Schenker and M. Chevion, Copper and zinc levels in normal and malignant tissues, Cancer, 1983, 52, 868-872.

2 S. Alam and S. L. Kelleher, Cellular mechanisms of zinc dysregulation: A perspective on zinc homeostasis as an etiological factor in the development and progression of breast cancer, Nutrients, 2012, 4, 875-903.

3 C. T. Chasapis, A. C. Luotsidou, C. A. Spiliopoulou and M. E. Stefanidou, Zinc and human health: an update, Arch. Toxicol., 2012, 86, 521-534.

4 J. L. L. Morgan, J. L. Skulan, G. W. Gordon, S. J. Romaniello, S. M. Smith and A. D. Anbar, Rapidly assessing changes in bone mineral balance using natural stable calcium isotopes, Proc. Natl. Acad. Sci. U. S. A., 2012, 109, 9989-9994.

5 P. A. Krayenbuehl, T. Walczyk, R. Schoenberg, F. von Blanckenburg and G. Schulthess, Hereditary hemochromatosis is reflected in the iron isotope composition of blood, Blood, 2005, 105, 3812-3816.
6 M. Aramendia, L. Rello, M. Resano and F. Vanhaecke, Isotopic analysis of $\mathrm{Cu}$ in serum samples for diagnosis of Wilson's disease: a pilot study, J. Anal. At. Spectrom., 2013, 28, 675-681.

7 S. L. Kelleher, N. H. McCormick, V. Velasquez and V. Lopez, Zinc in specialized secretory tissues: roles in the pancreas, prostate and mammary gland, Adv. Nutr., 2011, 2, 101-111.

8 V. Lopez, F. Foolad and S. L. Kelleher, ZnT2-overexpression represses the cytotoxic effects of zinc hyper-accumuation in malignant metallothionein-null T47D breast tumor cells, Cancer Lett., 2011, 304, 41-51.

9 C. M. Tinoco-Veras, M. S. Bezerra Sousa, B. B. da Silva, S. M. Franciscato Cozzolino, L. Viana Pires, J. A. Coelho Pimente, N. do Nascimento-Nogueira and D. do Nascimmento-Marreiro, Analysis of plasma and erythrocyte zinc levels in premenopausal women with breast cancer, Nutr. Hosp., 2011, 26, 293-297.

10 R. B. Georg, A. N. Halliday, E. Schauble and B. C. Reynolds, Silicon in the Earth's core, Nature, 2007, 447, 1102-1106.

11 B. L. Beard, C. M. Johnson, L. Cox, H. Sun, K. H. Nealson and C. Aguilar, Iron isotope biosignatures, Science, 1999, 285, 1889-1892.

12 S. Misra and P. N. Froelich, Lithium isotope history of Cenozoic seawater: changes in silicate weathering and reverse weathering, Science, 2012, 335, 818-823.

13 F. Albarède, P. Telouk, A. Lamboux, K. Jaouen and V. Balter, Isotopic evidence of unaccounted for $\mathrm{Fe}$ and $\mathrm{Cu}$ erythropoietic pathways, Metallomics, 2011, 3, 926-933.

14 K. Geraki, M. J. Farquharson and D. A. Bradley, Concentrations of $\mathrm{Fe}, \mathrm{Cu}$ and $\mathrm{Zn}$ in breast tissue: a synchrotron XRF study, Phys. Med. Biol., 2002, 47, 2327-2339.

15 J. M. Berg, Proposed structure for the zinc-binding domains from transcription factor IIIA and related proteins, Proc. Natl. Acad. Sci. U. S. A., 1988, 85, 99-102.

$16 \mathrm{~T}$. Fujii and F. Albarède, $\mathrm{Ab}$ initio calculation of the $\mathrm{Zn}$ isotope effect in phosphates, citrates and malates and applications to plants and soil, PLoS One, 2012, 7, e30726.

17 F. Moynier, T. Fujii, A. S. Shaw and M. Le Borgne, Heterogeneous distribution of natural zinc isotopes in mice, Metallomics, 2013, 5, 693-699.

18 D. J. Weiss, T. F. D. Mason, F. J. Zhao, G. J. D. Kirk, B. J. Coles and M. S. A. Horstwood, Isotopic discrimination of zinc in higher plants, New Phytol., 2005, 165, 703-710.

19 S. Lutsenko, Human copper homeostasis: a network of interconnected pathways, Curr. Opin. Chem. Biol., 2010, 14, 211-217.

20 L. Van Heghe, E. Engström, I. Rodushkin, C. Cloquet and F. Vanhaecke, Isotopic analysis of the metabolically relevant transition metals $\mathrm{Cu}, \mathrm{Fe}$ and $\mathrm{Zn}$ in human blood from vegetarians and omnivores using multi-collector ICP-mass spectrometry, J. Anal. At. Spectrom., 2012, 27, 1327-1334.

21 S. Rakoff-Nahoum, Why cancer and inflammation?, Yale J. Biol. Med., 2006, 79, 123-130.

22 C. Porta, P. Larghi, M. Rimoldi, M. G. Totaro, P. Allavena, A. Mantovani and A. Sica, Cellular and molecular pathways linking inflammation and cancer, Immunobiology, 2009, 214, 761-777.

23 T. Arnold, M. Schönbächler, M. Rehkämper, S. Dong, F.-J. Zhao, G. J. D. Kirk, B. J. Coles and D. J. Weiss, Measurement 
of zinc stable isotope ratios in biogeochemical matrices by double spike MC-ICPMS and determination of the isotope ratio pool available for plants from soil, Anal. Bioanal. Chem., 2010, 398, 3115-3125.

24 F. Larner, Y. Dogra, A. Dybowska, J. Fabrega, B. Stolpe, L. J. Bridgestock, R. Goodhead, D. J. Weiss, J. Moger, J. R. Lead, E. Valsami-Jones, C. R. Tyler, T. S. Galloway and M. Rehkämper, Tracing bioavailability of $\mathrm{ZnO}$ nanoparticles using stable isotope labelling, Environ. Sci. Technol., 2012, 46, 12137-12145.

25 F. Larner and M. Rehkämper, Evaluation of Stable Isotope Tracing for ZnO Nanomaterials - New constraints from high precision isotope analyses and modelling, Environ. Sci. Technol., 2012, 46, 4149-4158.

26 F. Larner, M. Rehkämper, B. J. Coles, K. Kreissig, D. J. Weiss, B. Sampson, C. Unsworth and S. Strekopytov, A new method for the separation of $\mathrm{Cu}$ prior to stable isotope analyses by MC-ICP-MS, J. Anal. At. Spectrom., 2011, 26, 1627-1632.

27 K. Moeller, R. Schoenberg, R.-B. Pedersen, D. Weiss and S. Dong, Calibration of the new certified reference materials ERM-AE633 and ERM-AE647 for copper and IRMM-3702 for zinc isotope amount ratio determinations, Geostand. Geoanal. Res., 2012, 36, 177-199. 